\title{
Implicit Causality and Consequentiality and Effect of Pronoun Resolution/Quality of Use among EFL Learners
}

\author{
Department of English-Mansoura University
}

\begin{abstract}
Implicit causality (IC) and Implicit Consequentiality (IR) are identified as universal attributes or elements that affect pronoun use because they arise from verb or adverb biases. Grounding this study was the notion that IC and IR influence noun resolution among EFL learners. Implicit Causality Biases has an effect on how EFL learners make pronoun resolution. The study seeks to test if implicit causality is also linked to co-reference bias, hence influencing pronoun resolution among EFL learners. This was a quantitative study through Survey Monkey questionnaires, targeting 30 respondents $(I C=n, 15$ and $I R=N, 15)$. The findings indicated that both $I C$ and $I R$ biases affected quality of pronoun resolution among EFL learners.
\end{abstract}

Key Words: Implicit Causality, Implicit Consequentiality, Biases, Pronoun Resolution. 


\section{السببية الضمنية وتبعات وتأثير قرار الضمير/ وجودة الاستخدام بين متعلمي اللغة الإججليزية كلغة}

\section{أجنبية}

ملخص

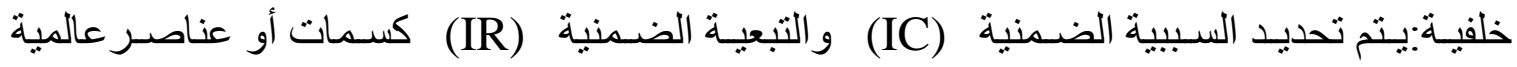
تؤثر على استخدام الضمبر لأنها ناشئة عن تحيز ات الفعل أو الظرف.

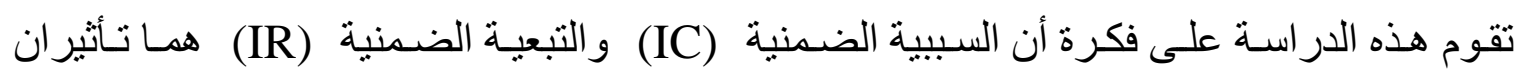
على دقة الأسماء بين متعلمي اللغة الإنجليزية كلغة أجنبية.

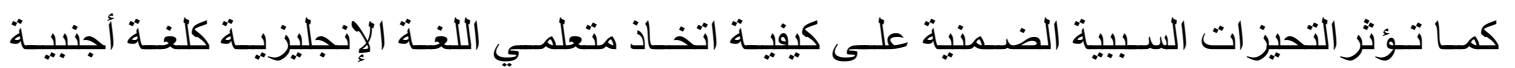

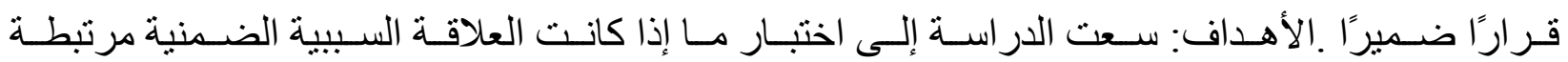

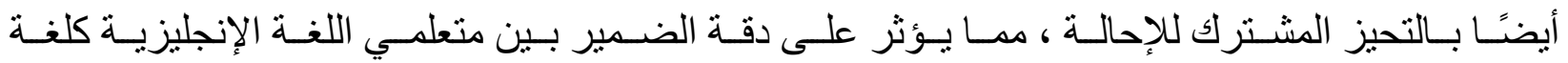

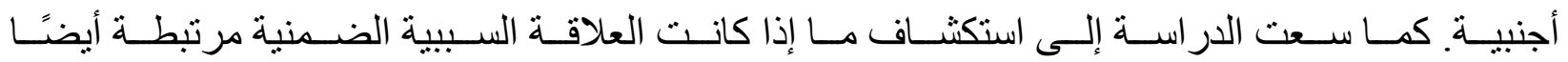

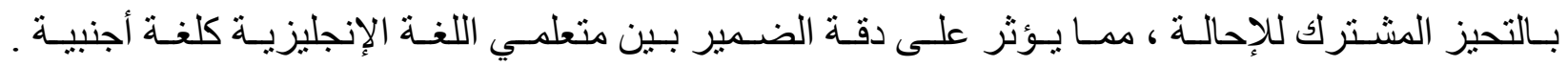

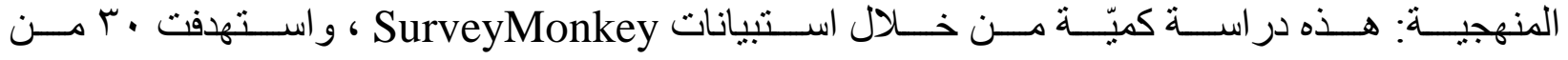

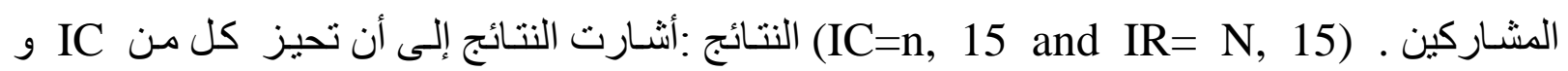
Iأتثر على جودة قرار الضمير بين متعلمي اللغة الإنجليزية كلغة أجنبية.

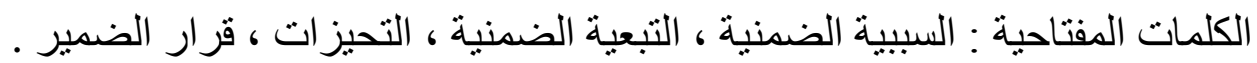




\section{INTRODUCTION}

How language users interpret pronouns is an area of research that has been explored to greater heights and perspectives. Most of these studies, as such, have been directed and focused on understanding as well as explaining strategies that individuals use in identifying pronominal referents (Nakamura, Arai, Hirose, \& Flynn, 2019). Conventionally, how individuals interpret pronouns, is influenced by the link between referring expressions and accessibility or salience of their antecedents (Cunnings, Fotiadou\&Tsimpli, 2017). Even though research has extensively focused on pronoun interpretation by native speakers, there is limited research or emphasis on non-native reference processing. Particularly, the inherent problem driving the current research is that resolving and using pronouns is a complex activity for L2 learners (Soares, Oliveira, Comesaña\& Costa, 2018).

Research has shown that language users or comprehenders depend on different cues in their bid to interpret referents in discourse contexts (Nakamura et al., 2019).Taking the case examples of: Tom made a surprise to Jane because he... and Mary hated Janet because she, it is easy to understand how individuals make meanings from the referent discourses. In the first sentence, there is no unambiguous information referring to the central character within the central item to which the pronoun is making reference. On the other hand, there are interpretations which would seem expressively natural in comparison to others, which is based on the probabilistic extrapolations regarding who could be implicitly responsible for the specific event or action (Cunnings et al., 2017). For example, with the reference to surprise, it is natural and easy to infer that Tom would be the most likely person to engage in the event or action in comparison to Jane. Hence, the use of noun he is more suitable referent to Tom in the causal dependent clause. On the other hand, when using or referring to the term hate event, as shown in the second sentence, it is evident that Janet is the central cause of the event, hence, consequently aligned with the "she" antecedent. This phenomenon is defined as implicit causality or re-mention bias (Quyen, 2017). Accordingly, those verbs denoting bias towards the subject defining a cause of action or event are defined as 'subject-biased' while those verbs showing bias towards the object are regarded as “object-biased' verbs (Kuehnast, \& Meier, 2019).

Verb-induced implicit causality or IC bias has been confirmed as a crucial factor with the reference resolution for first language or L1 (Cunnings et al., 2017). However, less evidence is reported for second language learning. Only few 
studies have examined implicit causality(Kuehnast, \& Meier, 2019). For example, Quyen (2017) engaged in an experimental design by treating the participants to online English tasks to identify the mismatch between the IC predisposition of target verb and the gender attributed to the subject pronoun within the subordinate causal clause. From their observation, the authors noted that the reading or quality of the reading was slowed down in scenarios with the dependent clause where the verb-bias was inconsistent with the pronoun. The study reported the similar effect on both L2 and L1 groups, but with slight difference in regions. However, the slowdown in reading clauses has been reported to be common with the L2 speakers for the subjects than the objectbiased verbs (Cheng, \&Almor, 2019). In so doing, earlier research has confirmed that L2 speakers depend on other cues which create the expectation for the subject re-mention, especially for familiar subject, parallel function preferences and first-mention (Quyen, 2017). Accordingly, L2 learners have been confirmed to be sensitive to verb-bias and as such, depend on this information in referential process for second languages (Kuehnast, \& Meier, 2019).

The same conclusions have been reported from studies likethose ofCheng and Almor (2017), whose exploration was on how Chinese-speaking learners use IC biases when arriving at their referential choices in tasks involving sentencecompletion English writing. From their findings, it was noted that L2 and native language users portrayed evident preferences for the bias-consistent continuations. The object-bias was found to be stronger among L2 but the similar results were reported for the subject-bias tasks of referencing (Contemori, 2019). In this case, existing research shows that L2 speakers have limited abilities in effectively integrating multiple information sources. Accordingly, non-native speakers have been shown and confirmed to have reduced or limited ability in generating expectations regarding the impeding or upcoming referents in processing discourse texts (Grüter, Rohde, \& Schafer, 2017). L2 speakers, particularly, have a higher tendency to strongly rely on subject or particularly first-mention bias in processing reference discourses. 


\section{The Current Study}

Since intentionality explains the IR and IC biases, implying that the two are attributed to causal inferences, it is vital for the current study to explore whether intentionality affects IR and IC biases (Kanwit, \&Geeslin, 2020). The use of pronouns, based on the IC biases, is best understood by taking into consideration how intentional events are explained by the agent-specific reasons, hence, explaining the same intentional behaviours or event begins by referring to the agent (the pronoun), and as the agent will he appearing within an active sentence. On the other hand, unintentional events are explained through causes which may be external or internal, then explanations directed at the unintentional event will not show a referential bias towards the agent (Niemi, Hartshorne, Gerstenberg, \& Young, 2016). The situation has been reported as different for the IR biases (Kanwit, \&Geeslin, 2020). Based on the folk concept of intentionality, an intentional behaviour is subject to the desire of an agent for a particular outcome (Kanwit, \&Geeslin, 2020). Hence, with interpersonal events involving patient and agent, the outcome is attributed to the patient. In this case, an agent is driven or influenced by intention to perform an action, of which the agent desires for the patient to be affected by the action for his or her desired action to be realized (Niemi et al., 2016). Once successfully performing the action, the patient becomes the entity by which direct influence is realized and as such, remains the key element of focus for the consequence (Kanwit, \&Geeslin, 2020).

The gender of those participating in the event equally has a profound influence or implication on re-mentions. For example, it has been noted that men are most likely to re-mention male individuals or pronouns denoting males in comparison to women (Kanwit, \&Geeslin, 2020). On the other hand, for the male being re-mentioned, they have been reported to be the most likely to be rementioned in the events associated with negative events like torment, kill, or hit (Niemi et al., 2016).

Another factor of consideration with rementions includes behaviours and attitudes of different people (Kanwit, \&Geeslin, 2020). Hence, it matters that people will associate a behaviour or cause of action with the negative quantifier or positive quantifier. 


\section{Objectives}

\section{Hence, this study sought to test whether:}

- Implicit Causality Biases have an effect on how EFL learners make pronoun resolution

- If implicit causality is also linked to co-referent bias, hence influencing pronoun resolution among EFL learners

\section{LITERATURE REVIEW}

The effect of implicit causality and consequentiality quality in EFL students' pronoun usage

Studies have shown that pronoun determination is not merely limited to morphosyantacticconstrictionsincluding number, sexual category and individual, but equally soft limitations including the first-mention predilection, subject preference, grammatical parallelism and, finally, Implicit Causality Bias (Kuehnast, \& Meier, 2019). IC bias refers to the bias, as indicated by interpersonal verbs, about the time proportions their object and subject arguments get re-mentioned in a specific sample of clarifications for the possibility described by the verb (Cheng \&Almor, 2017). Accordingly, within dependent clauses, the preferred referent of pronouns shows a systematic variance in their main clauses (Van Den Hoven, \&Ferstl, 2017). The preference for specific pronouns and verbs is a reflection of the intuition about the explicit meanings or attention that a language speaker wants to focus on (Kim,\&Grüter, 2019). Researchers have always focused their attention and debate as to whether the intuitions are defined by linguistic structure or whether this trend could be a result of high-level non-linguistic understanding (van den Hoven, \&Ferstl, 2017). However, evidence has shown that the later conclusion is true (Kuehnast, \& Meier, 2019). For one, implicit causality is subject to broader social judgmental task and as such, defined by the commonfamiliarity regarding the participants engaged in the particular event (Cheng \&Almor, 2017). Other studies have shown that implicit causality is subject to the linguistic structure while on equally has minimal influence from nonlinguistic cognition and general language (Kuehnast, \& Meier, 2019). In this respect, there is the inherent necessity to present a study outlining how IC or implicit causality is subject to intuitions and co-references by L2 learners. 
There are some studies that have tried to elaborate on the concept of implicit causality. For instance,Ferstl et al. (2011)elaborated that if a cluster of individuals is probed to continue, or even complete two sets of sentences, say 1(a) and 1(b), the exemplary verb, maze, would be linked to the individuals predilection for elucidations about the first-noun expression which renders amaze a Noun-Phraseassigning the cause to the subject (NP1) biased verb. On the other hand, love, in this sense, would be associated with the second noun phrase, which renders love to be Noun-Phrase assigning the cause to the object (NP2).

Nonetheless, IC is regarded as a soft constraint because sentences showing no congruence with the bias are specifically not viewed as ungrammatical, rather, these are uncommon and usually difficult to devise or use (Järvikivi, Van Gompel, \&Hyönä, 2017). On the other hand, some researchers have highlighted that IC bias could be a result of operationalrudiments of the hardcoded language and not the inference processes that entails the world knowledge (Niemi, Roussos, \& Young, 2019). Therefore, from a lexical semantic account perspective, learners usually depend on the semantic structure of the verb and combine this with the causal discourse relation in interpreting any ambiguous pronoun, or even in choosing a topic to which the sentence can be continued (Järvikivi et al., 2017). Although world knowledge has an effect in influencing pronoun resolution within the lexical semantic context, this is only possible when the initial interpretation has been revised (Hartshorne, 2014).

Despite most studies focusing on English language, IC has been reported to have an impact on pronoun co-reference in other languages; hence, this is a universal phenomenon or tenet to be used in understanding language acquisition (Cheng \&Almor, 2019). One of such studies was byJärvikivi et al.(2017) whose analysis from the sentence-completion on eight languages noted a cross-linguistic consistency with the IC bias, especially for the stimulus-experiencer (SE) and experience-stimulus (ES). The same findings and outcome have been noted with other languages like Spanish, Korean, Dutch, Finish, Japanese and Chinese among other common languages like German and Norwegian (Cheng \&Almor, 2019). In comparison to IC, few studies have been directed towards investigating Implicit Consequentiality (IR). Studies like (Kim, 2019), using the sentence-completion method, focused on fragmented NP2 or NP1 verbs, noted a recurring bias. Furthermore, studies have shown that there is the congruency effect on IR biases, 
just like noted in the IC studies(Niemi et al., 2019). The implication of this assertion is that reading is always slowed down with the pronoun inconsistency with the verb's IR's preferences or bias.

Another inherent consideration is that the strong evidence denoting the crucial role that connective has in determining IR and IC biases (Dery\& Bittner, 2016). For example, it is evident that IC biases are observable when the second clause is used as an explanatory clause, especially when indicated by the word "because" as a connective clause (van den Hoven, \&Ferstl, 2017). On the other hand, the IR biases or preferences are evident when the second clause used is a resultative clause, especially defined by the word "so" which functions as a as a connective clause (Schurz, \&Hertwig, 2019). Conversely, the biases do disappear with the use of a different connective(Schurz, \&Hertwig, 2019).

For instance, in an offline sentence completion and an online eye tracking study, Mendelovici (2018) investigated the effect of different connectives on IC biases. Theoffline results showed that strong IC biases were elicited only when the connective because was used: When the connective was "but"or "and", IC biases disappeared; when no connective was used, there was still IC biases but were much weaker than when the connectivebecause was used (Mendelovici, 2018). The online data corroborated the offline findings. When the connective was because, a congruency effect was observed such that participants experienced a reading delay when the subject pronoun in the subsequentphrase was inconsistent with the verb partiality. However, when the connective is "but"or "and", no such delay was found. Taken together, these findings demonstrate the importance of connectives, or arguably, discourse coherence relation, in determining referential preference. Hence, from the current evidence, it is vital to note that different connective denote or signifies different coherences in relations, for instance, because triggering an explanation coherence relation while so denoting or defining a result coherence or understanding relation (Mendelovici, 2018). In such type of relationship, IC is typical with the "because" connective word while IR with the "so" connective. This is an indication that IR and IC biases appear in result and explanation coherence relations (Dery\& Bittner, 2016). Hence, with a different coherence relation, there is also a referential biases variance according to these changes in relationships. 


\section{The Accounts of Implicit Causality and Consequentiality}

\section{Social Cognition Approach}

One of the central assertions of IC is that IC finds basis from the human causal cognition, which implies how individuals make causal inferences regarding behaviours (Schurz, \&Hertwig, 2019). Hence, IC is defined by the principles and concepts in the socio-psychological theories as well as models of causal reasoning. For one, Quyen (2017) noted that IC is linked with the universal cognitive schemata governing people's causal attribution, the stimulus-experiencer schema and the agent-patient schema. Hence, these two approaches or schemata are identified based on the inherent assumption that two basic kinds of interpersonal interaction occur: the emotional and actions states. Particularly, the agentpatient schema (AP) is associated with the actions and defines how people attribute the etiology of an interpersonal action to the agent, which is the individual who performs the action (Contemori, \&Dussias, 2019). This shows how action verbs render causality bias towards NP1. On the contrary, stimulusexperiencer (SE) schema is linked to states and as such, defines or determines how people associate an action cause to the stimulus, which entails the entity bringing about the change in the emotional state(Dery, \& Bittner, 2016). In so doing, SE verbs are associated with the NP1 causality bias while on the other hand, the ES verbs show causality bias towards NP2 (Dery, \& Bittner, 2016).

The causal schemata have been linked to the Co-Variation Model, which is defined as the attribution theory (Quyen, 2017). Based on this theory, behavior (including state or action), is ascribed to the cause and as such, co-varies with time (Dery\& Bittner, 2016). In this case, causes are delineated between the internal causes which are associated with the person and the external causes which are linked to the stimuli(Koornneef, Dotlačil, van den Broek, \& Sanders, 2016). An example is "John admires Sara" of which John becomes the person regarded as the internal cause while "Sara" becomes the inherent stimulus, as the external cause. This assessment and argument show that, whether the cause is associated with the stimulus or person, is subject to the co-variation variables of the distinctiveness and consensus (Quyen, 2017). In this regard, the term consensus is used as the behavioural co-variation within different individuals. For example, if many people are admiring "Sarah", then the consensus would be high 
but when only "John" is admiring "Sarah" then the consensus is weak or low. On the other hand, distinctiveness is associated with the covariant of the person's behaviours in all situations (Koornneef et al., 2016). Therefore, this is reported as high when the person engaging in the behaviour is only found within the particular situation, but becomes low when the individual can perform the specific behaviour in many occasions or situations (Van Den Hoven, \&Ferstl, 2017). For instance, if John's admiration is only specific to "Sara", the behavioural distinctiveness would be high' but this would be low is he has many people to admire apart from "Sara". Hence, using the co-variation principle, the cause behind behaviour is associated to the person when the distinctiveness or consensus is low but linked to the stimulus when the distinctiveness or consensus is high (Schurz, \&Hertwig, 2019).

\section{Discourse Comprehension}

Studies have shown that discourse comprehension is not confined to decoding the linguistic tenets of texts (Dery, \& Bittner, 2016). Rather, importantly, this process entails the construction of situation or mental model of the events being outlined and defined in the texts along with the relevant knowledge that comes activated through the comprehension process (Contemori, \&Dussias, 2019). From the existing research, it has also been shown that the five vital dimensions defining situational model include intentionality, causation, characters, space and time (Dery, \& Bittner, 2016). Besides, as noted by successive studies, it has been confirmed that every element of this dimension is crucial in discourse comprehension (Contemori, \&Dussias, 2019). The only gap in the existing studies is that they have been focused on understanding and explaining the role of these dimensions from a global perspective but not confining to local discourse, especially how individuals establish co-reference, which involves two elements referring to the same individual. Therefore, it is inherently vital to study how causation and intentionality plays a crucial rule in discourse understanding, and as such, outlining the degree to which the vital elements in the situational model influence the re-mention biases in the process by which the comprehender establishes co-reference, which in this case, entails the likelihood of mentioning a referant in the successive or subsequent discourse (Kuehnast\& Meier, 2019). In this case, how causality affects the comprehension of a discourse is best realized or comprehended by outlining the degree by which 
the intentionality of an event defines the re-mention biases being induced by both implicit causality and consequentiality. These two elements or areas have been reported and outlined to have closer and comprehensive relationships with the causal relations in discourse.

Intentionality ranks among the vital dimensions of the situational models. Readers have been found to play more attention to the character's intentions and goals as implicitly stated within the narrative (Dery, \& Bittner, 2016). Some of such an example would include "John wished to have a holiday'. In this case, remention and co-reference will be based on John's behaviours or intentions as mentioned in the narrative. Another case of consideration is that readers have been shown to pay faster attention and answer quickly to those questions probing the uncompleted intentions than when exposed to completed intentions (Kuehnast\& Meier, 2019). In so doing, this is an outright indication that readers find it easier to access the uncompleted intentions as compared to the completed intentions within their mental model. It is also shown that complement intentions are perceived as more available than the information irrelevant to intentions (Contemori, \&Dussias, 2019). Another case of consideration is that with the readers, both in native and non-native language, they are more inclined to pay closer attention to the subjective perception of the character towards the intentions (Kuehnast\& Meier, 2019). The current evidence outlines that the reader will always maintain the intentions of the character (in the story) as active within the situational models.

Also of profound consideration is that in addition to using Implicit Causality and consequentiality to track intentions, readers have equally been reported to be sensitive to the relationship between the actions and intentions of the character in any given story (Kim, \&Grüter, 2018). Therefore, when the action of the character is not in line with the intention, the reader turns out to be slow in understanding the inherent action (Zunino, Abusamra, \&Raiter, 2016). For example, the sentence "John was planning to go somewhere where he could sunbathe and swim", for the readers, they construct the meaning based on the sentence describing an action either in line with the intention, like "Johnny wanted to go to Florida" or even inconsistent with the action, which would be about him buying a ticket to Alaska. Using such an example, the results from (Kim, \&Grüter, 2018) indicated that the participants take a lot of time reading 
inconsistent sentence when compared to the consistent sentence. Furthermore, intentionality affects the speed and quality of reading because when there is an urgent intention, participants have always been reported to read the sentences faster (Van den Hoven, \&Ferstl, 2018).

\section{Intentionality and Causal Inferences}

The tendency of readers to track the discourse of the intentions of the characters is linked with their impulse or likelihood of establishing causal relations between the events presented in the discourse(Samland\&Waldmann, 2016). Particularly, research has shown that irrespective of the presence of the connectives signalling the causation, readers have a tendency of constantly updating their situational models by concluding or inferring the perceived causal relation between the presented events (Lush et al., 2019).Predominantly, discourses with causally related sentences have been confirmed to be better understood in comparison to the discourses that do not have casually connected contents(Samland\&Waldmann, 2016). In so doing, there is enough evidence confirming and indicating that causality becomes a vital element and concept device which allows individuals to construct or make sense of coherent presentation of text and as such, improves their comprehension and use of the same texts(Mendelovici, 2018). Understanding the discourse behind characters' intentions is vital because this helps to conclude or predict the intentions or the causal relations between events(Samland\&Waldmann, 2016). The implication is that intentions are regarded as what motivate people into actions(Lush et al., 2019). An example would be: "Mary" planned to buy some food: She then took to the grocery to store. In this particular example, it is easy to infer that the intention of "Mary" to buy some food triggered the action of visiting the grocery as this would be the chance or place for her to engage in the action or fulfill the goal of buying groceries. In so doing, the inherent understanding and comprehension of the character's intentions is crucial as it helps the reader in connecting the event's sequences in the discourse to develop an understandable or coherent causal structure(Samland\&Waldmann, 2016). 


\section{Implicit Causality and Consequentiality}

From the existing research, interpersonal verbs have been reported to portray implicit causal attribution. Certain verbs are associated with particular pronouns. For instance, the word fear is associated with ladies and this explains why re-mentioning or completion of sentences would use the pronoun "she". Nonetheless, earlier studies on IC reported that two types of psych verbs exist: the stimulus-experiencer (SE) and experience-stimulus (ES) (Cheng, \&Almor, 2017). These two categories are associated with different but stable IC biases. More so, the ES verbs, especially terms like fear show causality bias towards NP2 while SE verbs like frighten align with the causality bias towards NP1 (Kanwit, \&Geeslin, 2020). Conversely, action or agent-patient verbs are associated with the greater demonstration of IC variance biases. Most studies have been focussing on explaining IC with some accounting for IR (Cheng, 2016). Based on a number of such studies, it has been reported that IR and IC biases are subject to the lexicalsemantic properties defining the interpersonal verb, for instance, the verb argument structure(Kim \&Grüter, 2019). Particularly, IC has been found to be associated with the agent and stimulus thematic roles while for IR, this model is linked with the patient and experiencer thematic role.

\section{METHODOLOGY/EXPERIMENTS}

\section{Survey/Data Collection (Experimental Design)}

The survey experiment focused on understanding how intentionality affects IC biases. To understand how IC influences quality of pronoun use, the study engaged in the manipulation of intentionality using verbs denoting accidentally and deliberately. When the modification of a verb occurs such that it performs the function of reinforced intentionality, the actions that the adverb represent shows greater levels of intentionality, to show how the reader would easily infer about the agent performing the particular action under strong intentions. The use of pronouns, based on implicit causality, stems from the inherent assertion and notion that intentional events portray a referential bias targeted at the agent. Hence, as with regards to IC, the general assumption is that a prompt associated with adverbs that strengthen intentionality triggers more references towards the agent. In comparison, when a verb has been modified by an adverb denoting weaker intentionality, the reader is most likely to infer the action as being unintentional. 


\section{Method}

The study recruited 30 participants, online survey (SurveyMonkey online sentence-completion tasks), of non-native English speakers. All participants were undergraduate Arabic Speaking English learners as the L2 language. The experiment involved the students being required to complete a sentence and also translating a task. The study only used questionnaires whereby individuals had completed the study tasks. This study did not consider gender and age, but also considered their background of English language, at least 14 years on average.

Design and Material: In this experiment, two types of verbs were considered, the NP1-biasing IC (15 of them) and also the NP2-biasing IC verbs. The influence of the learner's native language stemming from lexical differences was addressed by selecting from a list of English verbs IC biases study. This was on the basis of first having the English verbs with lexical counterparts within each language. This was considered a necessity because L2 speakers barely have stable as well as consistent lexical items representations. This means that in the event that the native language of the target participants has competing information, then it would be impossible to have the predictions made effectively. The selected and identified verbs would be shared in both Arabic and English lexicons; implying that the selected verbs had higher lexical quality for the L2 participant's mental processing or representation; hence, the ease of retrieving the information. The second consideration was that every verb used would present a stronger IC bias for the referential direction, the same way in Arabic and English.

For the selected verbs, the study then arranged them in the NP1 (for the first category) and second category as NP2 on the basis of "because" causality. These carefully chosen NPs were used as familiar names inEnglish, coming from either gender. For every sentence-completion or item task, there was the alternation between a pronoun question or prompt and the free prompt condition. For the condition denoting a pronoun phrase or task, a pronoun denoting the matchingsexual category aligned and the study took the names in the initial or introductory clause being placed or aligned the word "because" as the connective clause. However, the free prompt condition involved not using any pronoun. 


\section{Coding:}

The sentence-completion data was coded based on the subjects. For instance, in the sentence continuation, NP provided in the succeedingphrase would be coded as representing or aligned with NP1 or first forebear or NP2 as the second precursor. The study used a first author and a trained English native speaker who had no idea about the study. From the reported findings, it was noted that the coding agreement was $92 \%$. In the multiple linear regressions, the t-tests were based on the correct score for each answer, which was rated between 1 and 5 ( 1 denoting low score and 5 high or correct score). NP1 and NP2 were 15 for each case.

\section{Results}

SUMMARY OUTPUT

\begin{tabular}{l|r}
\hline \multicolumn{2}{|c}{ Regression Statistics } \\
\hline Multiple R & 0.97886878 \\
\hline R Square & 0.958184089 \\
\hline Adjusted R Squal & 0.956635352 \\
\hline Standard Error & 1.797346009 \\
\hline Observations & 29 \\
\hline
\end{tabular}

ANOVA

\begin{tabular}{l|rccc|r}
\hline & $d f$ & \multicolumn{1}{c}{ SS } & MS & $F$ & Significance $F$ \\
\hline Regression & 1 & 1998.639847 & 1998.639847 & 618.687239 & $3.79292 E-20$ \\
\hline Residual & 27 & 87.222222222 & 3.230452675 & & \\
\hline Total & 28 & 2085.862069 & & & \\
\hline
\end{tabular}

\begin{tabular}{l|rrrrrrrr}
\hline & Coefficients & Standard Error & t Stat & P-value & \multicolumn{1}{l}{ Lower 95\% } & \multicolumn{2}{c}{ Upper 95\% } & Lower 95.0\% Upper 95.0\% \\
\hline Intercept & -2.462962963 & 0.779873393 & -3.158157444 & 0.00388547 & -4.063130991 & -0.86279494 & -4.06313099 & -0.8627949 \\
\hline X Variable 1 & 5.981481481 & 0.240476799 & 24.87342436 & $3.7929 E-20$ & 5.488063846 & 6.474899117 & 5.488063846 & 6.47489912 \\
\hline
\end{tabular}


The results below from linear regression show statistical significance of causality and its impacts or effects on pronoun use among EFL learners. In the first place, for the intercept, is 0.003 which denotes a positive correlation between the dependent and independent variable. In so doing, there is a concrete evidence highlighting how implicit causality influences or affects the quality by which EFL use or makes sense of pronouns. The Multiple $R$ is 0.979 , an indication that the relationship is strong and positive. Again, these data or results highlight how IC biases influence the quality of using pronouns. Hence, with a stronger $p$-value, $p<.003$ and $R=0.979$, the results confirm that IC biases have direct profound effect on the quality of pronoun use among EFL learners.

\section{t-Test Paired Sample test for means}

t-Test: Paired Two Sample for Means

\begin{tabular}{|l|r|r|}
\hline & Variable 1 & Variable 2 \\
\hline Mean & 1.8 & 4.066666667 \\
\hline Variance & 0.6 & 0.638095238 \\
\hline Observations & 15 & 15 \\
\hline Pearson Correlation & 0.831162774 & \\
\hline Hypothesized Mean Diffel & 0 & \\
\hline$d f$ & 14 & \\
\hline$t$ Stat & -19.17858654 & \\
\hline$P(T<=t)$ one-tail & $9.48596 \mathrm{E}-12$ & \\
\hline$t$ Critical one-tail & 1.761310136 & \\
\hline$P(T<=t)$ two-tail & $1.89719 \mathrm{E}-11$ & \\
\hline$t$ Critical two-tail & 2.144786688 & \\
\hline
\end{tabular}

In both variable 1 and 2 , the mean is above the middle range value, which shows positive correlation. In addition, the paired t-test also shows an above average variance, especially 0.6 , which is $60 \%$, denoting stronger relationships. The Pearson correlation is also positive, 0.83 , indicating a positive relationship between IC and IR in influencing the pronoun quality use among EFL speakers. 


\section{DISCUSSION}

The current study outlines how pronoun-use or co-references among L2 learners, especially EFL is based on the IC information or bias they derive from the provided context (Kuehnast\& Meier, 2019; Cheng, \&Almor, 2017 Niemi et al., 2019). Hence, when they identify the pronoun prompt or direction within the sentence fragment, these individuals are more inclined into completing the sentences using the NP1 references (Zunino et al., 2016). The findings support the existing evidence and literature supposition that IC bias, both in native and non-native language, more in pronoun resolution, is dependent on the strong coreferential connection between the subject and the pronoun (Van den Hoven, \&Ferstl, 2018). EFL learners, due to IC, can distinguish the IC biases of the two verbs types and use these differences in establishing the incoming co-references, which implies the subject of the sentence. Also of profound and necessary consideration is how L2 speakers, EFL in this context, use the implicit consequentiality in resolving pronouns or co-reference resolutions (Kuehnast\& Meier, 2019). Hence, the extent of pronoun use among EFL learners is based on their IR biases which they use in co-reference resolution; the greater the bias or co-reference, they more likely that they will identify the correct pronoun in the sentence completion task (Koornneef et al., 2016; Dery\& Bittner, 2016).

As was seen and found with IC biases, the IR strength of reference is affected by the form of referring, especially the NP1 references within the sentence completion or continuations which follow a pronoun task found to illicit more or stronger pronoun use and references (Van den Hoven, \&Ferstl, 2018). In so doing, the two case scenarios highlight the degree to which IC and IR biases consistently influences or defines pronoun use or co-reference. In so doing, IC and IR biases act independently in influencing an EFL's pronoun use (Dery\& Bittner, 2016). The current study has equally highlighted that to a greater extent and degree, L2 learners use the discourse information in generating re-mention biases. A major insight from this study is how L2 or EFL learners always show subject biases when making pronoun references (Koornneef et al., 2016; Dery\& Bittner, 2016). For example, if a context presents NP2 bias, it is most easy and evident for the $L 2$ learners to use and interpret the pronoun as referring to NP1, in comparison to the native speakers. The same is reported with the IR context to 
which L2 learners are reported likely to show NP1 bias in the resolution of pronouns after being presented with NP2-bsiang verbs (Dery\& Bittner, 2016). Hence, IC and IR show and confirm that L2 speakers have a greater deal and extent of subject bias when interpreting pronouns. This equally conforms to earlier studies that used SE verbs, of which such a consideration may limit the EFL learners from understating IR or IC biases (Kim, \&Grüter, 2018); such set of verbs are rare with other languages, but more common with the English language(Dery\& Bittner, 2016). This difference, particularly, is not about the verb, but particularly attributed to the challenges of $L 2$ resolution of pronouns relative to the subject, which depends on the IC and IR biases.

The current study conclusions equally help in understanding subject bias among L2 speakers when interpreting or using pronouns(Cheng, 2016). Mainly, the reason is attributed to the multi-linguistic influence, especially the EFL learners in this case. The reason is also challenged in with the results because within the IR and IC contexts, nouns are interpreted based on the discourse biases, of which bias is always directed towards NP1 especially when NP1-biasing verbs are provided and vice versa (Kim, \&Grüter, 2018). In this case, the native language of an individual, as such, is not reported or confirmed to have an influence on subject bias. Mainly, factors like gender of the person can explain why the two genders have particularly a certain bias (Kuehnast\& Meier, 2019).

On the other hand, a concern has been about how L2 speakers attribute subject bias when interpreting pronouns because they have a diminished ability in using IR and IC information in generating the discourse-level anticipations (Järvikivi et al., 2017; Niemi et al., 2019). Perhaps, others showed that individual L2 learners compensate of this reduced ability by focusing on NP1 references when compared to L1 speakers(Kim, 2019). Accordingly, this research has highlighted how the opposite is the case. L2 participants, in this case, have not shown native-dependent predictions in noun use or predictions (Koornneef et al., 2016;Dery\& Bittner, 2016). Hence, co-references and predictions or subject biases is due to other factors other than cross-lingual influence, which in this sense, is attributed to implicit causality and consequentiality (Quyen, 2017). 


\section{CONCLUSION}

Research has shown that language users or comprehenders depend on different cues in their bid to interpret referents in discourse contexts. Verbinduced implicit causality or IC bias has been confirmed as a crucial factor with the reference resolution for first language or L1. Speakers, particularly, have a higher tendency to strongly rely on subject or particularly first-mention bias in processing reference discourses. The current study has confirmed how pronounuse or co-references among L2 learners, especially EFL is based on the IC information or bias they derive from the provided context. Hence, when they identify the pronoun prompt or direction within the sentence fragment, these individuals are more inclined into completing the sentences using the NP1 references. EFL learners, due to IC, can distinguish the IC biases of the two verbs types and use these differences in establishing the incoming co-references, which implies the subject of the sentence. L2 speakers, EFL in this context, use the implicit consequentiality in resolving pronouns or co-reference resolutions. Hence, IC and IR show and confirm that L2 speakers have a greater deal and extent of subject bias when interpreting pronouns. In this case, the native language of an individual, as such, is not reported or confirmed to have an influence on subject bias. Primarily, factors like gender of the person can explain why the two genders have particularly a certain bias. Overall, the study has confirmed that IC and IR biases are the basis for pronoun resolution among nonnative speakers. In this case, the results are useful in explaining the differences in pronoun use and references among EFL learners. This presents profound implications for language teachers, more so EFL teachers to ensure that they tailor their lesson plans based on how IC and IR biases define or influence pronoun use as well as resolution among EFL learners. 


\section{References}

Cheng, W. (2016). Implicit causality andconsequentiality. In native And non-Native coreference Processing.

Cheng, W., \&Almor, A. (2017). The effect of implicit causality and consequentiality on nonnative pronoun resolution. Applied Psycholinguistics, 38(1), 1-26.

Cheng, W., \&Almor, A. (2019). A Bayesian approach to establishing coreference in second language discourse: Evidence from Implicit Causality and Consequentiality verbs. Bilingualism: Language and Cognition, 22(3), 456-475.

Contemori, C. (2019). Changing comprehenders' pronoun interpretations: Immediate and cumulative priming at the discourse level in L2 and native speakers of English. Second Language Research, 0267658319886644.

Contemori, C., \&Dussias, P. E. (2019). Prediction at the discourse level in Spanish-English Bilinguals: An Eye-Tracking Study. Frontiers in psychology, 10.

Cunnings, I., Fotiadou, G., \&Tsimpli, I. (2017). Anaphora resolution and reanalysis during L2 sentence processing: Evidence from the visual world paradigm. Studies in Second Language Acquisition, 39(4), 621-652.

Dery, J. E., \& Bittner, D. (2016). Time and causation in discourse: Temporal proximity, implicit causality, and re-mention biases. Journal of psycholinguistic research, 45(4), 883-899.

Ferstl, E. C., Garnham, A., \&Manouilidou, C. (2011). Implicit causality bias in English: A corpus of 300 verbs. Behavior Research Methods, 43(1), 124-135.

Grüter, T., Rohde, H., \& Schafer, A. J. (2017). Coreference and discourse coherence in L2: The roles of grammatical aspect and referential form. Linguistic Approaches to Bilingualism, 7(2), 199-229.

Hartshorne, J. K. (2014). What is implicit causality?. Language, Cognition and Neuroscience, 29(7), 804-824.

Järvikivi, J., van Gompel, R. P., \&Hyönä, J. (2017). The interplay of implicit causality, structural heuristics, and anaphor type in ambiguous pronoun resolution. Journal of psycholinguistic research, 46(3), 525-550.

Kanwit, M., \&Geeslin, K. L (2020). Sociolinguistic competence and interpreting variable structures in a second language: A study of the copula contrast in native and secondlanguage Spanish. Studies in Second Language Acquisition, 1-25.

Kim, H. (2019). Cross-Linguistic Activation In Korean L2 Learners'processing Of Remention Bias In English (Doctoral dissertation, University of Hawai? i at Mānoa). 
Kim, H., \&Grüter, T. (2018, November). Processing of remention biases in Korean learners of English. In Talk presented at the 43rd Annual Boston University Conference on Language Development, Boston University (pp. 2-4).

Kim, H., \&Grüter, T. (2019). Cross-linguistic activation of implicit causality biases in Korean learners of English. Bilingualism: Language and Cognition, 22(3), 441-455.

Kim, H., \&Grüter, T. (2019). Cross-linguistic activation of implicit causality biases in Korean learners of English. Bilingualism: Language and Cognition, 22(3), 441-455.

Koornneef, A., Dotlačil, J., van den Broek, P., \& Sanders, T. (2016). The influence of linguistic and cognitive factors on the time course of verb-based implicit causality. The Quarterly Journal of Experimental Psychology, 69(3), 455-481.

Kuehnast, M., \& Meier, E. (2019). Implicit causality of action verbs at the interface between conceptual structure and discourse coherence relations. Questions and Answers in Linguistics, 5(1), 11-35.

Lush, P., Roseboom, W., Cleeremans, A., Scott, R. B., Seth, A. K., \&Dienes, Z. (2019). Intentional binding as Bayesian cue combination: Testing predictions with trait individual differences. Journal of Experimental Psychology: Human Perception and Performance, 45(9), 1206.

Mendelovici, A. A. (2018). The phenomenal basis of intentionality. Oxford University Press.

Nakamura, C., Arai, M., Hirose, Y., \& Flynn, S. (2019). An Extra Cue Is Beneficial for Native Speakers but Can Be Disruptive for Second Language Learners: Integration of Prosody and Visual Context in Syntactic Ambiguity Resolution. Frontiers in Psychology, 10.

Niemi, L., Hartshorne, J. K., Gerstenberg, T., \& Young, L. (2016). Implicit measurement of motivated causal attribution. In CogSci.

Niemi, L., Roussos, G., \& Young, L. (2019). Political Partisanship Alters the Causality Implicit in Verb Meaning. Journal of Language and Social Psychology, 38(5-6), 809-819.

Quyen, N. T. (2017). Factors affecting pronoun resolution by Vietnamese EFL learners. Korean Journal of Applied Linguistics, 33(1), 111-135.

Samland, J., \&Waldmann, M. R. (2016). How prescriptive norms influence causal inferences. Cognition, 156, 164-176.

Schurz, G., \&Hertwig, R. (2019). Cognitive success: A consequentialist account of rationality in cognition. Topics in cognitive science, 11(1), 7-36.

Soares, A. P., Oliveira, H. M., Comesaña, M., \& Costa, A. S. (2018). Lexico-syntactic interactions in the resolution of relative clause ambiguities in a second language (L2): The role of cognate status and L2 proficiency. Psicológica Journal, 39(2), 164-197. 
van den Hoven, E., \&Ferstl, E. C. (2017). Association with explanation-conveying constructions predicts verbs' implicit causality biases. International Journal of Corpus Linguistics, 22(4), 521-550.

Van den Hoven, E., \&Ferstl, E. C. (2018). Discourse context modulates the effect of implicit causality on rementions. Language and Cognition, 10(4), 561-594.

Zunino, G. M., Abusamra, V., \&Raiter, A. (2016). Causality iconicity and continuity: the effects of prior world knowledge on the understanding of causal relations. Alfa Rev. linguíst, 60(2), 263-287. 


\section{Appendices}

\section{Appendix 1: Implicit Causality}

Complete the following sentences, and use the appropriate Pronoun (either he or she) :

1. John convinced Teacher Jane in the discussion because.....

2. Mary was disturbing Abel because........

3. Cecilia encouraged Janet because.......

4. Derek Injured James during play because......

5. Rachael was impressive to Elizabeth because......

6. Samuel scared Mary because.....

7. Johnny abused Ella because.....

8. Lydia lied to James because...

9. Nana got Erina tired because

10. Steve freighted Justin because

11. Chris Upset John because...

12. Janet Called Sara because......

13. Tim trusted Jenny because......

14. Katherene Gave Job problems because...

15. John slapped Kevin because...

16. Joe slapped his wife because..... 


\section{Appendix 2: Implicit Consequentiality Questionnaire}

Complete the following sentences with the appropriate action outcome (consequence)

1. Logan admired Jackson in childhood because

2. Matthew hate John at school because he.....

3. Cecilia encouraged Janet to go to the river because she...

4. Rachael was impressive to Elizabeth in the dance floor because she...

5. Samuel scared Mary in the evening because he.....

6. Johnny abused Ella on Facebook because he.....

7. Lydia lied to James at night because she...

8. Nana got Erina tired after school because she...

9. Steve freighted Justin at the bush because he..

10. Chris upset John in the playground because...

11. Janet called Sara at lunchtime because she......

12. Tim trusted Jenny with his book because he......

13. Katherene gave Job problems about hanging out with the bad boys because she...

14. John slapped Kevin at the door because he...

15. Joe beat his wife on Saturday because he... 


\section{Appendix 3: Implicit Causality (IC) Questionnaire Analysis}

\begin{tabular}{|c|c|c|}
\hline $\begin{array}{l}\text { 1. John convinced Teacher Jane in the discussion } \\
\text { because.... }\end{array}$ & Bias & Type \\
\hline 2. Mary was disturbing Abel because........ & NP1 & $\begin{array}{l}\text { SC (Sentence } \\
\text { Continuation) }\end{array}$ \\
\hline $\begin{array}{l}\text { 3. Cecilia encouraged Janet because....... } \\
\text { Derek Injured James during play because...... }\end{array}$ & NP1 & $\mathrm{SC}$ \\
\hline 4. Rachael was impressive to Elizabeth because...... & NP1 & SC \\
\hline 5. Samuel scared Mary because..... & NP1 & SC \\
\hline 6. Johnny abused Ella because..... & NP1 & SC \\
\hline 7. Lydia lied to James because... & NP1 & $\mathrm{SC}$ \\
\hline 8. Nana got Erina tired because & NP1 & $\mathrm{SC}$ \\
\hline 9. Steve freighted Justin because & NP1 & SC \\
\hline 10. Chris Upset John because... & NP1 & SC \\
\hline 11. Janet Called Sara because...... & NP1 & SC \\
\hline 12. Tim trusted Jenny because...... & NP1 & $\mathrm{SC}$ \\
\hline 13. Katherene Gave Job problems because... & NP1 & $\mathrm{SC}$ \\
\hline 14. John slapped Kevin because... & NP1 & SC \\
\hline 15. Joe slapped his wife because & NP1 & SC \\
\hline
\end{tabular}




\section{Appendix 4: Implicit Consequentiality (IR) Analysis}

\begin{tabular}{|c|c|c|}
\hline 1. Logan admired Jackson in childhood because & Bias & Type \\
\hline 2. Matthew hate John at school because he..... & NP2 & $\begin{array}{l}\text { SC (Sentence } \\
\text { Continuation) }\end{array}$ \\
\hline $\begin{array}{l}\text { 3. Cecilia encouraged Janet to go to the river because } \\
\text { she... }\end{array}$ & NP2 & $\mathrm{SC}$ \\
\hline $\begin{array}{l}\text { 4. Rachael was impressive to Elizabeth in the dance floor } \\
\text { because she... }\end{array}$ & NP2 & SC \\
\hline 5. Samuel scared Mary in the evening because he..... & NP2 & SC \\
\hline 6. Johnny abused Ella on Facebook because he..... & NP2 & SC \\
\hline 7. Lydia lied to James at night because she... & NP2 & $\mathrm{SC}$ \\
\hline 8. Nana got Erina tired after school because she... & NP2 & $\mathrm{SC}$ \\
\hline 9. Steve freighted Justin at the bush because he.. & NP2 & SC \\
\hline 10. Chris upset John in the playground because... & NP2 & SC \\
\hline 11. Janet called Sara at lunchtime because she...... & NP2 & SC \\
\hline 12. Tim trusted Jenny with his book because he..... & NP2 & $\mathrm{SC}$ \\
\hline $\begin{array}{l}\text { 13. Katherene gave Job problems about hanging out with } \\
\text { the bad boys because she... }\end{array}$ & NP2 & $\mathrm{SC}$ \\
\hline 14. John slapped Kevin at the door because he... & NP2 & SC \\
\hline 15. Joe beat his wife on Saturday because he... & NP2 & SC \\
\hline
\end{tabular}




\section{Appendix 5: Possible predicate/prediction}

\begin{tabular}{|l|l|l|}
\hline \multicolumn{2}{|l|}{ Type of predicate } & Predicate \\
\hline \multirow{2}{*}{ SC } & $S C$ & please, annoyance, upset, bore, sadden, humiliate, fascinate, scare, \\
& & insult, delight, fright, wonder \\
\cline { 2 - 4 } & Non- & apologize, approach, plead, request, swindle, admit, confuse, ask, \\
& SC & lie, misplace, bully, injur \\
\hline OB & Object- & disparage, jealous, fire, dislike, smash, discipline, change, mock, \\
& biased & rebuke, halt, prosecute, believe \\
\hline
\end{tabular}

\section{Appendix 6: Frequency scores of the predictions}

\begin{tabular}{|c|c|c|}
\hline \multicolumn{2}{|c|}{ Type of predicate } & Predicate \\
\hline \multirow[t]{2}{*}{ SC } & $S C$ & $\begin{array}{l}\text { Please(10), annoyance((12), upset(8), bore(13), sadden(14), } \\
\text { humiliate(12), fascinate (14), scare(14), insult(8), delight(9), fright(6), } \\
\text { wonder(12) }\end{array}$ \\
\hline & $\begin{array}{l}\text { Non- } \\
\text { SC }\end{array}$ & $\begin{array}{l}\text { Apologize (10), approach(9), plead(8), request(7), swindle(8), } \\
\operatorname{admit}(14), \operatorname{confuse}(12), \operatorname{ask}(15), \operatorname{lie}(13), \text { misplace(13), bully(7), } \\
\text { injury(13) }\end{array}$ \\
\hline OB & $\begin{array}{l}\text { Object- } \\
\text { biased }\end{array}$ & $\begin{array}{l}\text { disparage, (13)jealous(15), fire(13), dislike(12), } \operatorname{smash}(9), \\
\text { discipline(6), change(1), } \operatorname{mock}(7), \operatorname{rebuke}(8), \operatorname{halt}(7), \operatorname{prosecute}(4), \\
\text { believe(6) }\end{array}$ \\
\hline
\end{tabular}




\section{العلاقة السببية الضمنية والنتيجة الضمنية وقوة / جودة تأثير الاستخدام بين متعلمي اللغة الإنجليزية كلغة أجنبية}

\section{العلاقة السببية الضمنية والنتيجة الضمنية}

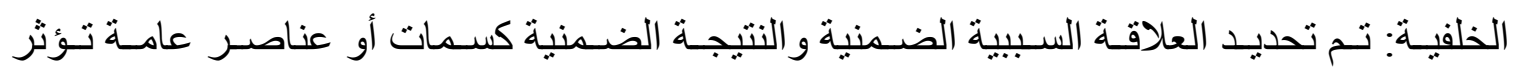

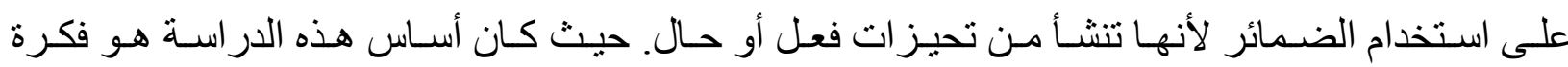

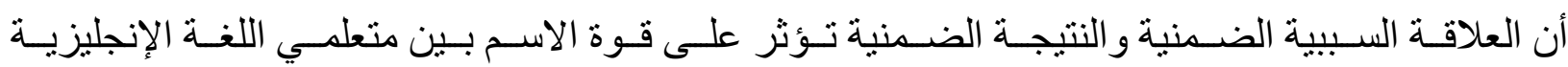

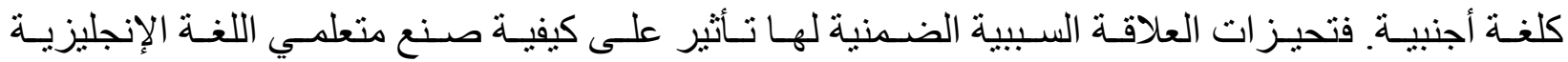

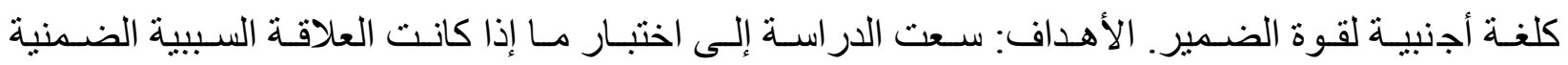

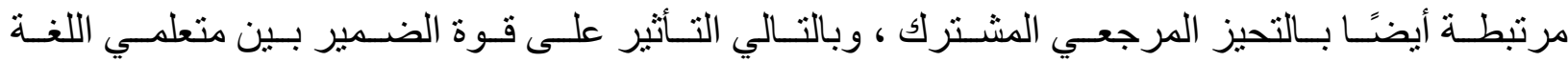

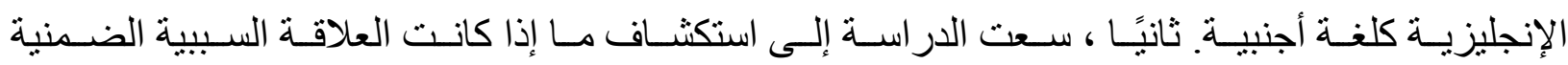

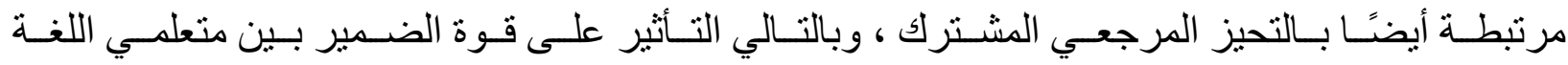

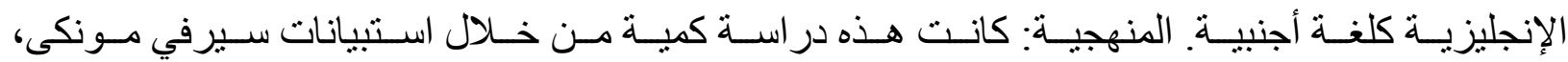

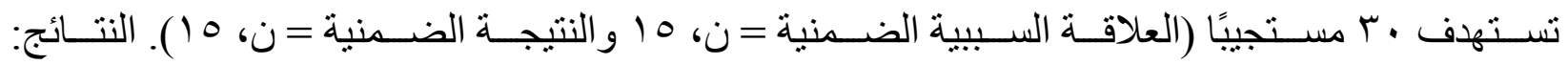

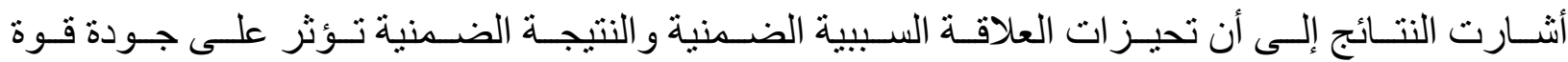
الضمير بين متعلمي اللغة الإنجليزية كلغة أجنبية. الكلمات المفتاحية : العلاقة السببية الضمنية ، النتيجة الضدنية ، التحيزات ، قوة الضمير. 